\title{
LA COMPARACIÓN INTERPERSONAL Y EL DERECHO PROCESAL CIVIL $^{*}$
}

\author{
Nicolás CARrasco Delgado**
}

RESUMEN: En el presente artículo se examina la relación existente entre el derecho procesal civil y la comparación interpersonal. Por medio de dicho examen, se tratará de despejar la crítica que se ha formulado a los criterios de eficiencia -fundamentalmente al criterio Kaldor-Hicks-, en cuanto generan situaciones de comparación interpersonal. Se indagará en la efectividad de dicha crítica, y a partir de los aportes de Amartya Sen, se concluirá en que todos los factores de decisión social, ya provengan de consideraciones de eficiencia o de justicia o equidad, están afectos a las mismas dificultades que impone dicha comparación. Con todo, se expresarán las razones por las que se considera que en el derecho procesal civil dichas dificultades tienden a reducirse.

Palabras Clave: Derecho Procesal Civil; Análisis Económico del Derecho; Criterio Kaldor-Hicks; Comparación Interpersonal; Teoría de elección social.

\section{THE INTERPERSONAL COMPARISON AND CIVIL Procedural LAW}

ABSTRACT: In this article, the existing relationship between procedural civil law and interpersonal comparison is examined. By means of the aforementioned examination, a critique of the efficiency criteria (essentially the Kaldor-Hicks criterion) which has been formulated when situations of interpersonal comparison are generated will be discredited. The efficacy of this criticism will be investigated, and starting with the contributions of Amartya Sen, it will be concluded that all of the factors of social decision, whether they originate from considerations of justice

\footnotetext{
* Fecha de recepción: 30 de diciembre de 2015.

Fecha de aceptación: 16 de agosto de 2016.

** Abogado y Licenciado en Ciencias Jurídicas y Sociales y Magíster en Derecho Económico de la Universidad de Chile. Doctorando en Derecho y Ciencias Políticas por la Universidad Autónoma de Madrid. Becario de Becas Chile para estudios de Doctorado en el Extranjero. Profesor Asistente de Derecho Procesal de la Universidad de Chile (Chile). Correo electrónico: ncarrascod@gmail.com
} 
or equity, are subject to the same difficulties which this comparison imposes. Nonetheless, reasons will be expressed for which in civil procedural law these difficulties tend to decrease.

KEY WORDS: Civil Procedural Law; Economic Analysis of Law; Kaldor-Hicks criterion; Interpersonal Comparison; Social Choice Theory.

Sumario: Introducción. 1) La regla imparcial de decisión y la comparación interpersonal de utilidades. 2) Unas palabras en relación a la objetividad y los juicios de valor. 3) En una primera mirada existe un panorama desalentador desde el derecho procesal. 4) ¿Existe algún factor que nos libere del panorama anterior? 5) Volvamos al proceso. Elementos que nos pueden dar una solución a la dificultad de las comparaciones interpersonales. Conclusiones.

\section{INTRODUCCIÓN}

En este artículo se busca desarrollar un aspecto que ha sido tratado largamente en economía y en filosofía moral, pero que no ha recibido mayor atención en el derecho procesal. Me refiero a la comparación interpersonal de ganancias y pérdidas. Resulta extraño que en la faz de litigación del derecho procesal, no se haya desarrollado un cuestionamiento en relación a la importancia, consecuencias y aplicación de la temática de las comparaciones interpersonales, más aún si el litigio conduce a la generación de ganadores y perdedores.

Dada la complejidad económica que este tratamiento posee, seguiremos fundamentalmente la línea argumentativa expuesta por Sen, ya que introduce la temática con una exposición de filosofía moral más cercana a la cuestión jurídica.

En lo sucesivo, nos dedicaremos al examen de la comparación interpersonal y las reglas imparciales de decisión (sección 1); luego, diremos unas palabras acerca de la objetividad y los juicios de valor que ella pretende dejar de lado (sección 2); posteriormente, daremos un primer vistazo al derecho procesal civil a la luz de las comparaciones interpersonales y describiremos un panorama desalentador en relación a que las dificultades que trae consigo dicha comparación aparecen presentes en tal área del derecho $^{1}$ (sección 3); en la sección 4, indagaremos algunas soluciones

1 Es importante dejar establecido que el presente artículo se refiere al proceso civil. Más allá de la cuestión sobre el tratamiento unitario del proceso, me interesa destacar un concepto residual del proceso civil. En este sentido, el proceso civil comprendería todo aquello que no es proceso penal. Este último concepto, por su parte, comprende "el instrumento mediante 
posibles a ese panorama desalentador, sin encontrarlas incluso cuando recurrimos a criterios de justicia, equidad e igualdad; Luego en la sección 5, daremos una nueva mirada al derecho procesal civil y desarrollaremos dos elementos que nos pueden ayudar a restar importancia a la problemática de las comparaciones interpersonales en el ámbito de tal área jurídica; finalizaremos con las conclusiones en la sección 6 .

\section{1) LA REGLA IMPARCIAL DE DECISIÓN Y LA COMPARACIÓN INTERPERSONAL DE UTILIDADES}

El criterio Kaldor-Hicks ${ }^{2}$ al introducir los conceptos de perdedores y ganadores, reingresa a la teoría de la decisión social, el problema de la comparación interpersonal de utilidades que Pareto pretendió dejar de lado (regla imparcial de decisión).

Tal comparación tiene la dificultad que puede transformarse en imposible, porque al suponer que la compensación de los ganadores a los perdedores es eventual, entonces, la comunidad se debe mover a una curva de indiferencia (que corresponde al conjunto de combinaciones de preferencias que resultan indiferentes para un sujeto o sociedad ${ }^{3}$ ) que no conoce y dado que somos ignorantes respecto de los ejes que conforman

el cual el ciudadano ejerce su derecho de defensa frente al poder punitivo del Estado”. MANASSEro, Ana y Muñoz, Hugo (2014) "El proceso como sistema en el estado de derecho". Revista Juridica, Vol. 2, No 1, p. 108.

De esta forma, en el proceso civil falta la existencia de ejercicio del poder punitivo del Estado.

Sobre esta materia puede verse: Couture, Eduardo (2010) Estudios de derecho procesal civil. Vol. I. Buenos Aires: Editorial La Ley, pp. 4-9.

2 Como sabemos Nicholas Kaldor formuló una regla de decisión de elección social que pretendía elegir entre dos situaciones en base a un criterio que significara una mejoría a Pareto. En este sentido, propuso lo siguiente: Un estado de cosas, X, es eficiente en términos de Kaldor, a otro estado de cosas, Z, si después de moverse de Z a X, los ganadores pueden compensar a los perdedores. Puede verse: Kaldor, Nicholas (1939) "Welfare Propositions of Economics and Interpersonal Comparisons of Utility". The Economic Journal, Vol. 49, N ${ }^{\circ}$ 195, pp. 549-552.

Se ha complementado el criterio de Nicholas Kaldor, con lo expuesto por John Hicks cuya propuesta está sostenida en términos de la cuestión de si los perdedores podrían sobornar a los ganadores para no permitir un movimiento hacia el nuevo estado social. O sea, el perdedor pudiera estar dispuesto a pagar al ganador, una cantidad de dinero determinada para impedir el paso al nuevo estado social (X), en la medida que dicha suma de dinero sea menor que la pérdida que sufre en el paso del estado social $(\mathrm{Z})$ a $(\mathrm{X})$. Al respecto, puede verse: (i) Hicks, John (1939) "The Foundations of Welfare Economics". The Economic Journal, Vol. 49, No 196, pp. 696-712; (ii) Hicks, John (1941) “The Rehabilitation of Consumers'Surplus”. Review of Economic Studies, Vol. 8, p. 108.

3 Muñoz, Félix (2002) “Teoría del Consumo”. En Cabañes, María Lucía (coordinadora): Microeconomía esencial. Barcelona: Ariel, pp. 72-73. 
dicha curva de indiferencia, entonces, no podemos comparar la distribución actual con una hipotética ${ }^{4}$.

Las comparaciones interpersonales para la economía suponen la posibilidad de ponderar los niveles de ganancias de bienestar marginales y las pérdidas marginales de bienestar de los individuos 5 . En este sentido, la idea de comparación interpersonal supone siempre la idea de una "mejor opción", en términos tales que esa mejor opción es elegida en el contexto de la comparación entre los sujetos implicados.

La comparación interpersonal puede ser cardinal, esto es, reflejar una cantidad $(1,2,3 \ldots n)$, u ordinal, que importa un orden (primero, segundo, tercero, etc.). En lo que sigue y para efectos de simplificación utilizaremos la comparación interpersonal cardinal, haciendo presente que la ordinal también se encuentra afecta a múltiples dificultades ${ }^{6}$.

Comencemos con un ejemplo que grafica una situación básica de comparación interpersonal cardinal. Supongamos que un juez debe resolver una situación actual $(\mathrm{X})$ y el factor de decisión es uno de aquellos que pretende generar un mayor bienestar social en el futuro. Tal juez enfrentado a dicho factor de decisión, optará por la alternativa que conduzca a ese mayor bienestar social. Si la disputa es entre A y B, el juez debe decidir si favorece a alguna de dichas personas en una situación futura (Y), en donde los valores de bienestar involucrados son los siguientes:

Tabla $\mathrm{N}$ o 1: Alternativas de elección social $(\mathrm{X}, \mathrm{Y})$ para 2 sujetos $(\mathrm{A}, \mathrm{B})$

\begin{tabular}{|l|l|l|}
\hline & A & B \\
\hline Situación Actual $(X)$ & 5 & 5 \\
\hline Situación Futura $(Y)$ & 4 & 10 \\
\hline
\end{tabular}

4 Jhunjhunwala, Bharat (1974) “Kaldor-Hicks-Scitovszky Criteria: A postmortem”. Southern Economic Journal, Vol. 40, Nº 3, pp. 495-496.

5 Desde la perspectiva de los sujetos como demandantes de ciertos bienes o servicios (por ejemplo, aquellos implicados en el cambio de estados sociales), tendremos que las ganancias marginales de utilidad corresponden al incremento de bienestar que se produce por una unidad adicional del bien o servicio en cuestión. Por su parte, las pérdidas marginales de utilidad corresponden a la disminución de bienestar que se produce por una unidad adicional de ese bien o servicio.

6 En este sentido, puede verse: $\mathrm{S}_{\mathrm{EN}}$, Amartya (1976) Elección colectiva y bienestar social. Madrid: Alianza Editorial, pp. 130-131.

Así, por ejemplo, se ha seńalado que de aplicar ordinalidad en el cálculo del criterio KaldorHicks incurriremos en la paradoja de Scitovsky. ZHOU, Qi (2005) The evolution of Efficiency Principle: From Utilitarianism to Wealth Maximization. Disponible en: http://ssrn.com/abstract $=870748$ [fecha de visita: 6 de noviembre de 2015], pp. 5-6. 
En este caso, el juez optará por la alternativa que propone $B$, ya que con ello se genera un aumento del bienestar social, debido a que al elegir la posición de B, el bienestar social total se incrementa. En efecto, el bienestar de B en el estado social (Y), es de \$10, en cambio, el bienestar social de $A$ en ese mismo estado social es de $\$ 4$. En este caso, la elección a favor de B se debe adoptar en el marco de un criterio que favorezca la existencia de mayor bienestar social, a pesar que A sea perdedor en la situación futura Y.

La comparación interpersonal en el supuesto anterior supone ponderar los niveles de ganancia individual de $\mathrm{B}$ en tránsito de un estado social a otro $(\mathrm{X}-\mathrm{Y}=\$ 5)$, y los niveles de pérdida de $\mathrm{A}$ en ese mismo tránsito $(\mathrm{X}-\mathrm{Y}=-\$ 1)$, lo que conduce a que una mejora interpersonal, medida en dinero, de $\$ 4$.

Mismo ejercicio puede realizarse en términos de agregado social. En este sentido, en la situación actual $\mathrm{X}$, la suma agregada de bienestar es de $\$ 10\left(\mathrm{X}_{\mathrm{A}}+\mathrm{X}_{\mathrm{B}}\right)$ y en la situación futura $\mathrm{Y}$, la suma agregada de bienestar es de $\$ 14\left(\mathrm{Y}_{\mathrm{A}}+\mathrm{Y}_{\mathrm{B}}\right)$, lo que conduce a un mayor bienestar social de $\$ 4$, según vimos. Esto, implica en el contexto de factores de decisión que favorezcan la eficiencia, que el tránsito desde el estado social $\mathrm{X}$ al estado social $\mathrm{Y}$, debe ser socialmente deseable.

\section{2) UNAS PALABRAS EN RELACIÓN A LA OBJETIVIDAD Y LOS JUICIOS DE VALOR}

Ahora bien, existe la pretensión de que las comparaciones interpersonales no son necesarias cuando nos enfrentamos a un criterio objetivo, esto es, a un criterio que no dependa de juicios de valor. En este sentido, los criterios Paretianos al pretender establecer reglas que fueran unánimemente aceptadas por todos, buscaban un factor imparcial de resolución de elecciones colectivas. Así, por ejemplo, el óptimo de Pareto al establecer el tránsito desde la sociedad X a la sociedad Y, sin que existieran perdedores, buscaba precisamente que no existiera oposición al movimiento que nos condujera a la sociedad Y.

Obviamente dicha oposición existirá cuando aplicando un criterio de decisión social se generan perdedores (Kaldor-Hicks), ya que estos no tendrían motivo para aceptar su nueva calidad de perdedores, y al existir disenso entre los miembros de la sociedad entonces tenemos juicios de valores disímiles respecto de la aceptación del criterio de decisión social utilizado. Para unos el juicio de valor será favorable a la utilización del criterio -normalmente los ganadores-y para otros, el juicio de valor será 
desfavorable a la utilización del criterio -normalmente los perdedores-, manteniendo todo el resto constante.

Dicho disenso se complejiza debido a que tal como acredita Qi Zhou, si la medición cardinal de utilidad es usada, el análisis de KaldorHicks genera el problema de la imposibilidad de medición de la comparación interpersonal de utilidades, ya que si la utilidad es definida como satisfacción, no existirá ningún estándar que permita mensurarla ${ }^{7}$.

Dicha noción de satisfacción es subjetiva. Ello ha sido considerado por Harsanyi, quien ha llamado la atención acerca que las dificultades de las comparaciones interpersonales surgen no solamente de las preferencias de las personas, sino también de la manera en que las diferencias de las personas afectan la satisfacción que ellas derivan de cada situación.

De esta forma, Harsanyi señala que cuando un individuo A prefiere la situación $\mathrm{X}$ a la situación $\mathrm{Y}$, en circunstancias que otro individuo $\mathrm{B}$ prefiere la situación $\mathrm{Y}$ a la situación $\mathrm{X}$, ello se puede deber a que el individuo A prefiere la situación $\mathrm{X}$ porque en dicho estado social obtiene mayor bienestar, y al mismo tiempo, puede ocurrir que el individuo B prefiera el estado social Y, no porque prefiera estrictamente dicho estado social, sino simplemente por evitar llegar al estado social X, en donde sabe que tendrá un bienestar individual escaso, aun cuando no conozca con certeza el bienestar individual que obtendrá en Y. Tales dificultades psicológicas pueden ir variando y no son empíricamente demostrables ${ }^{8}$.

En este sentido, tal imposibilidad empírica deriva del hecho que existan juicios de valor involucrados en relación al criterio sobre qué factor debería primar en una determinada decisión -en el caso analizado precedentemente, aquel que genera mayor bienestar social-. De esta forma, si la discusión recae en juicios de valor, entonces, no sería posible por medio de un análisis científico comparar las magnitudes de (in)satisfacción de A y B. Esto ha sido puesto de relieve por Robbins:

"Pero supongamos que nosotros diferimos acerca de la satisfacción derivada para A desde un ingreso de $\$ 1,000$, y la satisfacción derivada para B desde un ingreso de dos veces esa magnitud. Preguntar a ellos no debería darnos ninguna solución. Si suponemos que ellos difieren, A debe concluir que tiene más satisfacción que B. En cir-

Zноч (2005) 3-5.

También, Hovenkamps cuando declara que "desde que las comparaciones interpersonales de utilidad son en general imposibles"; traducción del autor. En su lengua original: "since interpersonal comparisons of cardinal utilies are generally imposible". HovenKAMP, Herbert (1990) "Positivism in Law \& Economics". California Law Review, Vol. 78, No 4, pp. 840-841. parison of Utility". The Journal of Political Economy, Vol. 63, No 4, pp. 317-318. 
cunstancias que $\mathrm{B}$ debe concluir que, por el contrario, tiene más satisfacción que A. Nosotros no necesitamos ser un esclavo de la teoría behaviourists para alcanzar la conclusión que no hay evidencia científica en este asunto. No hay manera de testear las magnitudes de satisfacción de A en comparación con las de B"?.

De esta forma, siguiendo a Robbins ${ }^{10}$ y en relación al ejemplo anterior, B será de aquellos que considere favorablemente la utilización del criterio que selecciona su alternativa y A será de aquellos que considere desfavorablemente la utilización de ese criterio. Por ello, A podría preguntarse ¿por qué favorecer una opción que implica un juicio de valor favorable a un mayor bienestar social? Tal pregunta es formulada precisamente porque la regla imparcial de decisión no se encuentra comprendida en un criterio que genera ganadores y perdedores, como lo es, el criterio Kaldor-Hicks.

\section{3) EN UNA PRIMERA MIRADA EXISTE UN PANORAMA DESALENTADOR DESDE EL DERECHO PROCESAL CIVIL}

Tal como hemos señalado al comparar interpersonalmente estamos ponderando los niveles de ganancias o bienestar y las pérdidas marginales de bienestar de los individuos. En el ejemplo anterior supusimos esa comparación de acuerdo a modificaciones en riqueza, ya que medimos las alternativas y su variación en el tránsito desde la situación $\mathrm{X}$ a $\mathrm{Y}$, en términos de dinero (pesos, \$). Ello implica que somos capaces por medio de alguna convención social cualquiera (mercado, fijación regulatoria, $\mathrm{u}$ otra), de alcanzar una valoración de bienes y servicios.

$9 \quad$ Traducción del autor. En su lengua original: "But suppose that we differed about the satisfaction derived by $A$ from an income of $\$ 1,000, y$ la satisfaction derived by $B$ from an income of twice that magnitude. Asking them would provide no solution. Supposing they differed. A might urge that he had more satisfaction than $B$ at the margin. While $B$ might urge that, on the contrary, he had more satisfaction than $A$. We do not need to be slavish behaviourists to realice that here is no scientific evidence. There is no means of testing the magnitude of $A$ 's satisfaction as compared with B's ... ". Robins, Lionel (1932) An Essay on the Nature and Significance of Economic Science. Londres: Macmillan \& Co., Limited, pp. 123-124.

10 Sobre este punto se encuentra conteste Harsanyi (1955) 320, al señalar que "Al mismo tiempo, el profesor Robbins está claramente en lo correcto cuando él sostiene que proposiciones que afirman ser comparación interpersonal de utilidades a menudo contienen puramente elementos convencionales basados sobre juicios de valor éticos o politicos" Traducción del autor. En su lengua original: "At the same time, Professor Robbins is clearly right when he maintains that propositions which purport to be interpersonal comparisons of utiliy often contain a purely conventional element base don ethical o political value judgments". 
Sin embargo, no todo lo que existe en este mundo es susceptible de una valoración pecuniaria que podamos expresarla en dinero ${ }^{11}$. En tales supuestos hablaremos de "utilidad". Con ello queremos reflejar todas las valoraciones que poseen las personas tengan o no una apreciación pecuniaria, lo que incluye bienes y servicios que no se transan en un mercado, como por ejemplo, bienes que están protegidos por reglas de inviolabilidad, tales como, el derecho de su propio cuerpo o el derecho a reclamar la paternidad.

El derecho procesal civil reconoce que las disputas que conoce el sistema de administración de justicia (sea público o privado) pueden catalogarse como de cuantía determinada o indeterminada. En este sentido, existen una serie de reglas con el objeto de determinar esa cuantía en las causas judiciales ${ }^{12}$, lo que no impide que el legislador haya considerado que en ciertos casos existan materias que "no están sujetas a una determinada apreciación pecuniaria"13.

La idea detrás de lo anterior es que una variación de riqueza no es completamente correlativa a una variación de utilidad, precisamente porque no se trata de conceptos sinónimos y adicionalmente, debido a que cada persona valorará de manera distinta un cambio en las situaciones de riqueza, en razón de la ley de la utilidad marginal decreciente. Esta se traduce en que a medida que una persona adquiere unidades adicionales de un bien o servicio, la utilidad aumenta pero en una tasa decreciente. Así, el concepto de riqueza (medido por lo que las personas adquieren) y utilidad (el provecho que las personas obtienen de bienes o servicios, incluso aquellos que no poseen apreciación pecuniaria), se van diferenciando al producirse tales incrementos marginales o adicionales ${ }^{14}$.

11 En relación con el problema de la comparación interpersonal, Hovenkamp señala que incluso en muchas situaciones resulta prohibido realizar comparaciones que involucren mediciones de mercado, precisamente porque concurren situaciones de no mercado. Hovenkamp (1990) 834-835.

12 Artículos 115 a 132, ambos inclusive, del Código Orgánico de Tribunales.

13 En este sentido, el artículo 130 del Código de Procedimiento Civil, señala como ejemplos de ello " 10 Las cuestiones relativas al estado civil de las personas; $2^{\circ}$ Las relacionadas con la separación judicial o de bienes entre marido y mujer, o con la crianza y cuidado de los hijos; $3^{\circ}$ Las que versen sobre validez o nulidad de disposiciones testamentarias, sobre petición de herencia, o sobre apertura y protocolización de un testamento y demás relacionadas con la apertura de la sucesión, y $4^{\circ}$ Las relativas al nombramiento de tutores y curadores, a la administración de estos funcionarios, a su responsabilidad, a sus excusas y a su remoción".

14 Shäfer, Hans-Bernd y Oтt, Claus (2004) The Economic Analysis of Civil Law. Londres: Edward Elgar, pp. 35-36. 
Al respecto, Dworkin declara: "la riqueza es conceptualmente independiente de la utilidad" 15 . En el mismo sentido, Richard Posner indica que: "Lerner observó que dado que no sabemos hasta qué punto se extienden las funciones de utilidad marginal de las personas, la mejor hipótesis de trabajo es suponer que no guardan relación con el ingreso" ${ }^{16}$.

De esta forma, podemos apreciar que una comparación interpersonal resulta compleja. Ya que las modificaciones que sufren A y B entre las situaciones $\mathrm{X}$ e $\mathrm{Y}$, no resultan susceptibles de medir en términos de utilidad en relación a cuánto significa en el caso concreto una pérdida de $\$ 1$ para A, y una ganancia de $\$ 4$ para $B$. Recordemos que según Robbins, no es posible entregar herramientas científicas para llevar a cabo esa comparación.

Con todo, se ha elaborado muchos intentos con miras a resolver esa dificultad. Dichos intentos han sido sistematizados por Amartya Sen en su libro "Elección colectiva y bienestar social", que utilizaremos como referencia en lo sucesivo. Un intento en este sentido, es formulado por Goodman y Markowitz ${ }^{17}$, quienes asumen que cada individuo tiene solamente un número finito de niveles de indiferencia o "niveles de discreción". De esta forma, un cambio desde un nivel al siguiente representa la mínima diferencia que es perceptible para el individuo. Agregan que dicha asunción no es irrazonable, porque no podemos esperar que los individuos tengan una cantidad excesiva de niveles de discreción ${ }^{18}$.

Sin embargo, Sen desestima dicho método en razón de que no resulta posible observar todos los niveles de discriminación de un individuo. Asimismo, el análisis formulado por Goodman y Markowitz depende de la disponibilidad de alternativas existentes, y finalmente, no es éticamente aceptable un cambio de niveles de discreción para todos los individuos, dado que cada uno tiene diferentes sensibilidades de percepción ${ }^{19}$.

Otro método de cardinalización corresponde al de Von NeumannMorgenstern $^{20}$. Según Sen, dicho método bajo situaciones de riesgo se traduce en que suponiendo que el comportamiento de una persona satis-

15 Dworkin, Ronald (1998) “¿Es la riqueza un valor?”. Revista Estudios Públicos, N 69, p. 269.

16 Posner, Richard (1998) “Utilitarismo, Economía y Teoría del Derecho”. Revista Estudios Públicos, No 69, p. 227.

17 Goodman, Leo y Markowitz, Harry (1952) "Social Welfare Functions Based on Individual Rankings”. American Journal of Sociology, Vol. 58, No 3, pp. 257-262.

Goodman/Markowitz (1952) 259.

SEN (1976) 120.

Von Neumann, John y Morgenstern, Oskar (1944) Theory of Games and Economic Behavior. Princeton: Princeton University Press, p. 625. 
face un conjunto de postulados claramente definibles ${ }^{21}$, podemos encontrar un conjunto tal de números de utilidad correspondientes al conjunto de alternativas, en términos tales que su comportamiento puede tomarse como un intento por maximizar la esperanza matemática de estos números de utilidad ${ }^{22}$.

Sin embargo, tal criterio no evita las problemáticas de la comparación interpersonal, porque sigue suponiendo la posibilidad de ponderar las medidas de utilidad de diferentes personas, considerando la capacidad de ellas para obtener satisfacción.

Sen termina su repaso concluyéndose que solamente sería posible una comparación interpersonal cardinal parcial. Al respecto, la crítica de Robbins a los mecanismos de comparabilidad no distingue entre comparabilidad total y parcial ${ }^{23}$, de forma tal que esta última forma de comparabilidad no fue objeto de consideraciones críticas especiales por parte de Robbins.

En este sentido, Sen ha propuesto introducir variabilidad limitada en las unidades de bienestar relativas de diferentes individuos y manejar, no correspondencias de uno a uno, sino correspondencias de muchos a mu$\operatorname{chos}^{24}$.

Para explicar dicha idea, Sen elabora dos tablas. La primera de ellas refleja los indicadores de bienes tentativos para tres individuos $\mathrm{A}, \mathrm{B}$ y $\mathrm{C}$, en tres alternativas $\mathrm{y}, \mathrm{x}, \mathrm{z}$.

\section{Tabla No 2 Indicadores de bienestar tentativos}

\begin{tabular}{|l|l|l|l|}
\hline \multirow{2}{*}{ Individuos } & Alternativas & \multicolumn{2}{|l|}{} \\
\cline { 2 - 4 } & $\mathrm{X}$ & $\mathrm{Y}$ & $\mathrm{Z}$ \\
\hline $\mathrm{A}$ & 1 & 0,90 & 0 \\
\hline $\mathrm{B}$ & 1 & 0,88 & 0 \\
\hline $\mathrm{C}$ & 0 & 0,95 & 1 \\
\hline
\end{tabular}

Fuente: Amartya, Sen (1976) Elección colectiva y bienestar social. Madrid: Alianza Universal, p. 127

\footnotetext{
21 Para un estudio de los postulados del método de cardinalización de Von Neumann-Morgenstern, puede verse: Marschak, Jacob (1950) "Rational Behavior, Uncertain Prospects, and Measurable Utility”. Econometrica, Vol. 18, No 2, pp. 111-141.

SEN (1976) 121.

Robbins (1932) 121-127.

SEN (1976) 127.
} 
En la segunda tabla, Sen expresa las diferencias de bienestar tentativas que se desprenden de primera estimación:

Tabla No 2: Diferencias de bienestar tentativas

\begin{tabular}{|l|l|l|l|}
\hline \multirow{4}{*}{ Individuos } & Alternativas & \multicolumn{2}{|l|}{} \\
\cline { 2 - 4 } & $\mathrm{X} \mathrm{e} \mathrm{Y}$ & Y y Z & Z y X \\
\hline A & 0,10 & 0,90 & $-1,00$ \\
\hline $\mathrm{B}$ & 0,12 & 0,88 & $-1,00$ \\
\hline $\mathrm{C}$ & $-0,95$ & $-0,05$ & 1,00 \\
\hline
\end{tabular}

Fuente: Amartya, Sen (1976) Elección colectiva y bienestar social. Madrid: Alianza Universal, p. 128.

En adelante, transcribo las conclusiones de Sen: "Primero tomamos $x$ e $y$ para compararlas. Bajo la primera estimación la suma de la diferencia de bienestar de los tres individuos es - 0,73, de modo que $y$ parece ser la preferida. Sin embargo, podemos cambiar estas medidas de diferencia de bienestar. La combinación más favorable para $x$ frente a $y$ es doblar las medidas de A y B y reducir a la mitad las medidas de C. Esto da un intervalo de $-0,035$, de modo que $y$ tiene aun una suma de bienestar mayor que $x$. De aquí que $y$ pueda ser declarada mejor que $x$, según el criterio de agregación con el grado de variabilidad especificado"25. "En cuanto a y y $z$, la combinación mas favorable para $z$ es reducir a la mitad las medidas de bienestar de A y B y duplicar las de C, pero aun así la suma de bienestar para $y$ es mayor que para $z$ por 0,79 . De aquí que $y$ sea mejor que $z^{\prime 26}$. "Sin embargo, la comparación de $z$ y $x$ no es concluyente. Tal como figura en las Tablas, $x$ tiene una suma de bienestar mayor, pero si reducimos a la mitad las medidas de bienestar de A y B y duplicamos la de C, obtenemos una diferencia a favor de $z$ y no de $x$. De aquí que la relación de agregación deba ser declarada incompleta en este par. Pero esto no afecta a la elección entre $x, y \mathrm{y} z$, puesto que $\mathrm{y}$ es mejor que $x \mathrm{y} z$. Es decir, hay un único elemento óptimo"27.

Bajo tal propuesta podemos alcanzar una elección óptima sin caer en los extremos de no comparabilidad ni comparabilidad completa. Incluso aun cuando en el caso analizado el grado de comparabilidad $(d)$ es bajísimo: $d=0,0625$.

\footnotetext{
$25 \quad$ SEN (1976) 128.

26 SEN (1976) 128-129.

$27 \quad$ SEN (1976) 129.
} 
Con tales consideraciones nos enfrentamos con una nueva traba. En el acto de adjudicación no se puede realizar un ejercicio de comparabilidad parcial como el propuesto por Sen, porque nos enfrentamos a 2 individuos y el análisis mencionado, supone que desechamos la correspondencia de uno a uno, como es, por ejemplo, aquella que existe entre demandante y demandado.

Nuevamente el Derecho procesal al momento de la decisión final nos muestra que los intentos por superar las dificultades de la comparación interpersonal no van de la mano con su formulación.

Incluso, más allá de si es posible o no dicha comparación -análisis que excede los propósitos de este artículo-, podemos concluir que en el acto jurídico procesal de decisión jurisdiccional necesariamente nos enfrentaremos a las problemáticas de comparación interpersonal. Lo anterior, por la sencilla razón de que el acto de adjudicación genera ganadores y perdedores.

De esta forma, cabe desestimar aquellas críticas a los criterios de eficiencia que se basan en que dichos criterios conducen a comparaciones interpersonales, ya que más que una objeción a la aplicación de la eficiencia en el contexto de decisión procesal, estarían simplemente constatando una realidad. Entonces, dichas críticas pierden sentido, salvo que puedan ofrecer una salida distinta al panorama anterior. Nadie lo ha intentado.

\section{3) ¿EXISTE ALGÚN FACTOR QUE NOS LIBERE DEL PANORAMA ANTERIOR?}

Tal como hemos visto, algunos han criticado factores de decisión que atienden al mayor bienestar social, toda vez que, producen juicios de valor y, por tanto, comparación interpersonal. Sin embargo, lo que deseamos expresar es que cualquiera sea el factor de decisión judicial a utilizar en un proceso civil, no se salvará de una crítica similar.

En este sentido, si quisiéramos utilizar criterios de justicia o equidad concretizados en la buena fe, en un proceso de reivindicación de cosas muebles en contra de terceros a consecuencia de la resolución judicialmente declarada de un contrato (artículos 1490 y 1491 del Código Civil chileno ${ }^{28}$ ), también tendríamos ganadores y perdedores y podríamos perfectamente examinar sus condiciones antes y después del juicio en tér-

\footnotetext{
28 Normas que regulan la acción reivindicatoria de una resolución judicialmente declarada respecto de terceros poseedores, atendiendo al carácter de buena o mala fe de tales terceros.
} 
minos de comparación interpersonal de riqueza (el bienestar o pérdida del ganador o perdedor).

Por otro lado, si quisiéramos utilizar criterios de equidad maximin como el de Rawls, tampoco nos libramos de la comparación interpersonal. En efecto, el examen de Rawls acerca del criterio de equidad emana de aquello que los individuos acordarían en una posición original. Tal estado es hipotético, ya que allí concurren todos los individuos bajo un velo de ignorancia, que les impide conocer su situación personal y el estado que le correspondería en la sociedad que resulte por ellos acordada. En este sentido, los criterios de justicia que Rawls deriva de ese acuerdo adoptado en la posición original, serían los siguientes:

- El primer principio de justicia se traduce en que: "Cada persona ha de tener un derecho igual al más extenso sistema total de libertades básicas compatible con un sistema similar de libertad para todos" 29 .

- El segundo principio de justicia se forma en términos tales que: "Las desigualdades económicas y sociales han de ser estructuradas de manera que sean para: a) mayor beneficio de los menos aventajados, de acuerdo con un principio de ahorro justo, y b) unidos a los cargos y funciones asequibles a todos, en condiciones de justa igualdad de oportunidades" 30 .

Con todo, aplicando el segundo criterio llegamos necesariamente a una comparación interpersonal de carácter ordinal. En efecto, el criterio maximin, supone la maximización del bienestar del peor situado ${ }^{31}$, lo que indudablemente reintroduce la necesidad de establecer un orden, a efecto de resolver quien ocupa tal situación. Todo ello, a pesar de que Rawls trata de diferenciar sus principios de justicia de la comparación interpersonal de utilidad ${ }^{32}$.

29 Rawls, John (2006) Teoría de la Justicia. Traducción de María D. González. Buenos Aires: Fondo de Cultura Económica, p. 280.

30 RaWls (2006) 280.

31 En este sentido, Rawls (2006) 281, al formular sus principios de justicia señala "Todos los bienes sociales primarios -libertad, igualdad de oportunidades, renta, riqueza, y las bases de respeto mutuo-, han de ser distribuidos de un modo igual, a menos que una distribución desigual de uno o de todos estos bienes redunde en beneficio de los menos aventajados".

32 "La concepción de utilidad extiende el principio de opción racional de una persona al caso donde existe una pluralidad de personas, ya que en este último caso, lo que para una persona cuenta como sus ventajas deben ahora ser compensadas con sus pérdidas iniciales o subsecuentes, por el contrario, la justicia excluye una análoga clase de razonamiento entre las individuos". Traducción del autor. En su lengua original: "The conception of utility extends the principle of rational choice for one person to the case where there is a plurality of persons, for one person may properly count his adventages now as compensating for his own losses earlier or subsequently, but justice excludes the analogous kind of reasoning between 
En este sentido, Sen demuestra que la propuesta de Rawls no escapa de la comparación interpersonal: "Para cualquier estado social, ordenamos los individuos según su bienestar y escogemos al individuo peor situado, anotando su nivel de bienestar para compararlo con el del individuo peor situación en otro estado social distinto. Mientras cada individuo tenga una ordenación completa y exista algún método para ordenar el bienestar de individuos diferentes, es decir, para hacer comparaciones interpersonales de niveles de bienestar, podemos obtener una ordenación social completa"33.

De esta forma, uno de los criterios de equidad basados en igualdad más importantes que se han intentado en la filosofía moral -en este sentido, Rawls explícitamente establece que el segundo principio de justicia supone una prioridad de la justicia sobre la eficiencia y el bienestar ${ }^{34}$,, tampoco se libera del peso de las comparaciones interpersonales. Así, uno de los cuestionamientos habituales que se hace a la eficiencia -el de generar comparaciones interpersonales-, aplica respecto de una de las teorías emblema de dichas objeciones, en relación a un tema que para tales objetores sería sensible.

Incluso más, si utilizamos factores de profunda igualdad como los sostenidos por Dworkin, referente crítico de las teorías utilitaristas precisamente por reintroducir el elemento de comparación interpersonal ${ }^{35}$, el resultado desalentador es el mismo.

En efecto, Dworkin ha propuesto una concepción igualitaria de igualdad de recursos, que propugna que "el gobierno logre asegurar para cada ciudadano una igual participación en los recursos para que cada persona los use como desee para hacer su vida más provechosa según su propia perspectiva" ${ }^{36}$. Según Dworkin dicha concepción permite delimitar debidamente los ámbitos de responsabilidad pública y privada, ya que: "requieren que el gobierno trate a las personas como iguales en el

persons". Rawls, John (1999) Collected Papers. Editor Samuel Freeman. Cambridge: Harvard University Press, p. 95.

33 SEN (1976) 169

34 "Segunda Norma de Prioridad (La Prioridad de la Justicia sobre la Eficiencia y el Bienestar). El segundo principio de la justicia es lexicográficamente anterior al principio de eficiencia, y al de maximizar la suma de ventas; y la igualdad de oportunidades es anterior al principio de diferencia. Hay dos casos: a) la desigualdad de oportunidades debe aumentar las oportunidades de aquellos que tengan menos; b) una cantidad excesiva de ahorro debe, de acuerdo con un examen previo, mitigar el peso de aquellos que soportan esta carga". RAwls (2006) 280-281.

35 DwOrkin (1998) 289-290.

36 Dworkin, Ronald (2008) El imperio de la justicia. Barcelona: Gedisa Editorial, p. 213. 
esquema de propiedad que designa, pero no exige que las personas traten a otras como iguales al utilizar aquello que el esquema les asigna (... )"37.

Pues bien, dicha propuesta establece que el ámbito de responsabilidad de lo público se debe traducir en el tratamiento como iguales de las personas que conforman una comunidad. Una vez que el Estado haya asignado un esquema de derechos de acuerdo a tal criterio, las transacciones posteriores serán determinadas libremente (sin coacción) por las personas, traduciéndose esto último, en el ámbito de responsabilidad privada.

En lo que se refiere a la perspectiva pública de la concepción de justicia de igualdad de Dworkin, la misma al suponer un tratamiento como iguales cuando el Estado establece el esquema de derechos de propiedad, se traduce en un juicio valor a favor de dicha concepción igualitaria. Se trata de una pauta de diseño institucional que impone una asignación determinada sin consideración a las particulares preferencias de los sujetos que se encuentran afectos a tal esquema. Se supone que ese juicio de valor es reconocido por quienes deseen una distribución igualitaria en la riqueza, pero no necesariamente importa una aceptación unánime de parte de aquellos que pudieran no desear esa distribución. De hecho, no solo no es evidente que todos deseen un esquema como el propuesto de Dworkin, y no me refiero solo a aquellos que buscarían asignar los derechos en base a factores no igualitarios - como por ejemplo, pudiera ser atender la asignación de derechos en razón de criterios de linaje, de imposición inicial, de reconocimiento social, etc.-, sino que incluso a aquellos que pudieran ser desventajados en su habilidad de obtener provecho de tal asignación y que es razonable que deseen que la asignación inicial no fuera igualitaria en los recursos, sino que dependiera de las necesidades ${ }^{38}$ y especiales desventajas de cada uno ${ }^{39}$.

Dworkin no soluciona la cuestión de cómo alcanzar unanimidad respecto del esquema propiedad de igual distribución de riqueza que propone. En este sentido, solamente funda dicha unanimidad en la existencia de supuestas "convicciones familiares" 40 que inducirían a aceptar su formulación. Sin embargo, y volviendo a Robbins, dichas "convicciones" no son más que cuestiones valorativas no verificables que suponen imposicio-

\footnotetext{
37 DwORKIN (2008) 213.

38 Zimmerling, Ruth (1990) “Necesidades básicas y relativismo moral”. Doxa, No 7, pp. 35 54.

39 Riвотta, Silvana (2011) "Necesidades, igualdad y justicia. Construyendo una propuesta igualitaria de necesidades básicas". Derecho y Libertades, No 24, II, pp. 259-299.

40 DWORKIN (2008) 213.
} 
nes normativas de unos -aquellos que aceptarían el esquema de distribución igualitario de Dworkin-, sobre otros -aquellos que desestimarían dicho esquema de distribución igualitario-. Lo anterior, es relevante porque debemos valorar las preferencias de unos y otros para saber el resultado al que nos conduce tal propuesta, y al proceder de esa forma, reintroducimos la comparación interpersonal ${ }^{41}$, lo mismo que Dworkin criticaba.

Finalmente, podemos referir los principios de gradación de justicia de Suppes ${ }^{42}$, que determina reglas éticas de comportamiento respecto de supuestos de participación de dos personas. El principio de gradación se expresa, según Sen, de la siguiente forma: $x$ es mas justa que $y$ según el individuo $i$, si (a) prefiere estar él mismo en $x$ mejor que en $y$ y también prefiere ser el otro individuo en $x$ mejor que en $y$, o (b) prefiere estar él mismo en $x$ mejor que él mismo en $y^{43}$. En este sentido, Suppes sugiere dos reglas de comportamiento orientado a la justicia:

- Primera regla: Si los principios de gradación de justicia de los dos individuos dan la misma ordenación parcial estricta, y si hay un punto de justicia único, entonces debe elegirse la estrategia perteneciente a cada punto ${ }^{44}$.

- Segunda regla: Si para cualquier jugador el conjunto de estrategias saturadas de justicia no es vacío, debe elegir una ${ }^{45}$.

A pesar de que el principio de gradación de justicia de Supples cumple con el requisito de universalización de Hare ${ }^{46}$ y evita la comparación interpersonal de bienestar, toda vez que las preferencias son realizadas independientemente si se realizan considerando su propia posición o la de otra persona, no considera las diferencias personales en las preferencias. Para eliminar ese problema, Sen propone que una preferencia que suponga "ponerse en el lugar del otro debería equivaler a tener sus mismas

41 En el mismo sentido Harsanyi (1955) 320, cuando señala: "Por ejemplo, la asunción de que los diferentes individuos tienen la misma susceptibilidad por la satisfacción a menudo expresa solamente el juicio de valor del igualitarismo que todos los individuos deberían ser tratados igualmente ... ". Traducción del autor. En su lengua original: "For instance, the assumption that different individuals have the same susceptibility to satisfaction often expresses only the egalitarian value judgment that all individuals should be treated equally ... ”.

42 Suppes, Patrick (1966) "Some Formal Models of Grading Principles". Synthese, Vol. 16, No 3, pp. 284-306.

SEN (1976) 180-181.

SEN (1976) 181.

SEN (1976) 181.

Según el cual, quien sostiene una enunciación normativa que asume una regla para la satisfacción de los intereses de otras personas debe aceptar las consecuencias que dicha regla le traerá en el caso eventual que él se encuentre en las situaciones de esas otras personas. Puede verse: Hare, Richard (2003) The Language of Morales. Oxford: Oxford University Press, pp. 129-134, pp. 187-197. 
circunstancias objetivas y a identificarse también con él en términos de sus rasgos subjetivos" ${ }^{47}$, sin embargo, en ese caso reingresamos la comparación interpersonal de utilidades, ya que deberíamos considerar la comparación de los estados $x$ e $y$, para las dos personas en cuestión.

Como consecuencia de todo lo señalado es que Amartya Sen concluye que tanto los criterios de justicia y equidad, así como los parámetros utilitaristas no se encuentran exentos de la realización de comparación interpersonales:

"Así pues, la versión ampliada del principio de gradación es muy rica. Aunque no da una ordenación social completa, exprime al máximo el uso de la dominancia (o desigualdad vectorial), que es el elemento común en el criterio maximin, utilitarismo y otros procedimientos de elección colectiva que implican comparabilidad interpersonal" 48 .

La crítica a los criterios de eficiencia no paretianos, en base a que los mismos conducirían a realizar tales clases de comparaciones, no solamente no aplicarían en el contexto del proceso según vimos precedentemente, sino que además, quedaría vacía de contenido porque no existiría teoría moral que no pudiera verse afectada por tales cuestionamientos.

\section{5) Volvamos al PROCESo Civil. Elementos QUE NOS PUEDEN DAR UNA SOLUCIÓN A LA DIFICULTAD DE LAS COMPARACIONES INTERPERSONALES}

Con todo, sabiendo que cualquier criterio de decisión judicial que utilicemos nos reintroducirá en las complejidades de las comparaciones interpersonales, de todas formas no perdemos las esperanzas. En este sentido, debemos volver al derecho procesal civil. Y cuando reingresamos en esta área jurídica nos damos cuenta de dos elementos que pueden dar una solución al problema: (i) el primero de ellos, es que consideraremos al criterio Kaldor-Hicks, como el factor de decisión social que da contenido a la eficiencia. Al respecto, dicho criterio es el factor de eficiencia mayormente utilizado ${ }^{49}$ y opera como un instrumento que conduce en ciertos

\footnotetext{
SEN (1976) 184.

SEN (1976) 169.

En este sentido: (i) Coleman, Jules (2004) "Los Fundamentos del Bienestar". Revista de Derechos y Humanidades, $\mathrm{N}^{\circ}$ 10, p. 24, cuando señala "El estándar básico para determinar la eficiencia en el laworeconomics es el criterio de Kaldor-Hicks y no el de Pareto"; (ii) Coleman, Jules (1980) "Efficiency, Exchange, and Auction: Philosophic Aspects of the Economic Approach to Law". California Law Review. Vol. 68, N² 2, pp. 221-249, y (iii) Schäfer/OtT (2004) 37.
} 
subconjuntos normativos a alcanzar un fin de mayor bienestar social con más certeza que otro instrumento, y (ii) en segundo lugar, la decisión del juez opera en el proceso civil con márgenes de error que permiten que la elección judicial opere en búsqueda no de la mejor elección, sino, a lo menos, de una que opere "como si" fuese la mejor.

Veremos a continuación que el elemento (i) genera que la comparación interpersonal no es relevante en ciertos subconjuntos normativos, y que el elemento (ii) determina que el proceso civil está configurado para una elección acíclica ("como sî"), lo que disminuye las problemáticas de una comparación interpersonal. Veamos.

En relación al primer elemento mencionado, hemos sostenido ${ }^{50}$ que la eficiencia es un factor de decisión judicial en ciertos subconjuntos normativos determinados (por ejemplo, derecho procesal concursal51, libre competencia ${ }^{52}$, ciertas regulaciones procesales ${ }^{53}$ y sectores económicos regulados ${ }^{54}$ ). También sostenemos que en tales subconjuntos normativos,

50 Puede verse: (i) Carrasco, Nicolás y NúÑez, Raúl (2015) "Análisis Económico de la Administración de Justicia. ¿La justicia como bien público o privado?”. Revista Chilena de Derecho, Vol. 42, No 2, pp. 595-613, y (ii) Carrasco, Nicolás y Núñez, Raúl (2014) "Conceptos generales del Análisis Económico del Derecho Concursal". En Carrasco, Nicolás y Núñez, Raúl (coordinadores): Presente y Futuro del Derecho Procesal Concursal Chileno. Una revisión desde el Análisis Económico del Derecho. Santiago: Editorial LegalPublishing, pp. 30-53.

51 En este sentido, puede verse: (i) Cornelli, Francesca, y Felli, Leonardo (1997) "Ex ante efficiency of bankruptcy procedures”. European Economic Review, Vol. 41, pp. 476-477; (ii) Hart, Oliver (2000) "Different approaches to Bankruptcy". National Bureu of Economic Research. Disponible en: http://www.nber.org/papers/w7921. [fecha de visita: 4 de diciembre de 2015], p. 18; (iii) Aghion, Philippe; Hart, Oliver; Moore, John (1992) "The Economics of Bankruptcy Reform”. Journal of Law, Economics and Organization, Vol. 8, No 3, pp. 523-546; (iv) Peinado, Juan Ignacio (2006) "Cooperación y pillaje en el concurso". En Peinado, Juan Ignacio y Valenzuela, Francisco Javier (coordinadores): Estudios de Derecho Concursal. Madrid: Marcial Pons, p. 239, y (v) CABrillo, Francisco (1998) Quiebra y liquidación de empresas. Madrid: Unión Editorial, p. 45.

52 (i) TAPIA, Javier y Cordero, Luis (2015) "La revisión judicial de las decisiones regulatorias: Una mirada institucional”. Revista Estudios Públicos, No 139, p. 53; (ii) Montt, Santiago (2010) "El TDLC como ente regulador del comercio". Documento de Trabajo No 1. Santiago: REGCOM, Facultad de Derecho de la Universidad de Chile, p. 1, y (iii) AgüEro, Francisco; García de Cortázar, Verónica; García, William (2013) "Control Jurisdiccional de la potestad normativa del Tribunal de Defensa de la Libre Competencia en materia de telecomunicaciones". Informe en Derecho No 26. Santiago: REGCOM, Facultad de Derecho de la Universidad de Chile, pp. 3-6.

53 Carrasco, Nicolás (2010) "La contracautela: Una mirada desde el análisis económico del derecho procesal”. Revista de Derecho y Humanidades, Vol. 2, N 16, pp. 171-185.

54 Por ejemplo, en la normativa sobre fijación tarifaria de servicios sanitarios, contenida en DFL N $\mathrm{N}^{\circ} 70$ del Ministerio de Obras Públicas, de 30 de diciembre de 1998. En este sentido, el Título I de tal regulación señala que se encontrarán "sujetos a fijación de tarifas los servicios de agua potable y de alcantarillado de aguas servidas, prestados por servicios públicos y empresas de servicio público, en adelante, prestadores tanto a usuarios finales, como a otros que actúen como intermediarios respecto de aquellos". Tal normativa establece de manera explícita que la 
a falta de una especificación legal de la eficiencia, esta adquiere contenido conceptual por medio del criterio Kaldor-Hicks, el mismo que según hemos visto se encuentra afecto al problema de la comparación interpersonal, y que como hemos indicado, constituye el factor de eficiencia mayormente utilizado ${ }^{55}$.

Pues bien, considerando tales premisas es que podemos señalar que la eficiencia -conceptualizada por medio del criterio Kaldor-Hicks-, constituye un instrumento apropiado para alcanzar objetivos de mayor bienestar social, en los subconjuntos normativos en que ese objetivo se persigue, sin necesidad que el juez compruebe efectivamente si tal objetivo se concretizó con la dictación de la sentencia en la que hizo uso de tal criterio.

En este sentido, los elementos del criterio Kaldor-Hicks son: (i) La existencia de una decisión social56; (ii) Que esa decisión social genere ganadores y perdedores ${ }^{57}$; (iii) Que los ganadores se encuentren en condi-

finalidad del proceso de determinación de valores por la prestación de servicios sanitarios es conducir al establecimiento de una tarifa "eficiente". En este sentido, los artículos 4 y 8 del DFL No 70.

55 Ver nota No 51.

56 Es importante hacer notar dos herramientas procesales que permiten que el juez civil pueda conocer las preferencias de las partes que litigan ante él. Esto es relevante con miras a solucionar las dificultades que la decisión en base a eficiencia pueden generar: (i) La primera es la provisionalidad de las decisiones civiles. Esto es, cuando ellas pueden ser modificadas por una variación o cambio de las circunstancias. En tales casos el juez volverá a conocer de un asunto por segunda vez. Ello genera que la discusión sobre la materia respectiva opera en un juego repetitivo que entrega mayor información al tribunal para decidir correctamente. Cuando el juez conoce en segunda oportunidad accederá de mejor forma a las preferencias de las partes litigantes, toda vez que, podrá valorar el comportamiento subsecuente de aquellos. Tal comportamiento será sincero porque normalmente las partes no actúan estratégicamente pensando que sus actuaciones serán valoradas nuevamente por el juez a causa de un cambio de las circunstancias; (ii) La segunda herramienta es la internalización que la ley impone a las partes para soportar ciertas cargas durante el juicio civil. De esta forma, la ley fuerza a que las preferencias de los litigantes se manifiesten no más allá de ciertas etapas o momentos procesales. La idea en esta herramienta es diversa a la lógica de juego repetitivo de la herramienta (i). Acá existe un juego único que induce a las partes a manifestar sus pretensiones o defensas so pena de perder. Un ejemplo, lo constituye los momentos procesales para rendir cierta prueba (artículo 207 del Código de Procedimiento Civil).

57 Un ejemplo de lo que se entiende por ganadores o perdedores en el contexto del derecho procesal concursal corresponde al artículo 229 de la Ley No 20.720. Según esa norma la Junta de Acreedores en el contexto de un procedimiento concursal de liquidación puede acordar no perseverar en la persecución de ciertos bienes que pertenecen a la masa activa, cuando el costo estimado para recuperarlos sea mayor que el beneficio esperado de su realización. Tal norma establece una regla de generación de riqueza social conceptualmente idéntica al criterio Kaldor-Hicks. En efecto, si un acreedor discute la adopción de ese acuerdo ante el juez del concurso y este falla a favor del acuerdo de no persecución, entonces, uno de los ganadores con dicha decisión es el tercero poseedor del bien del deudor y los perdedores son aquellos acreedores que no lograron que tal bien fuera reintegrado a la masa. El fundamento en que el juez puede descansar su decisión se lo entrega la norma; en este caso, que el costo de persecución es mayor que el beneficio de la liquidación de ese bien. En otras palabras, el juez favorece el estado social X (no persecución del bien), porque entiende 
ciones de compensar a los perdedores, y (iv) Que de existir esa compensación los ganadores sigan siendo ganadores.

En lo que aquí interesa, cuando referimos a la no necesidad de comprobación empírica de los efectos de las decisiones judiciales adoptadas en base una conceptualización Kaldor-Hicks de eficiencia, nos ubicamos en una etapa posterior a la toma de decisión social, esto es, una etapa en donde el juez ha dictado sentencia, lo que significa que ya se ha realizado una atribución inmediata de ganadores-perdedores ${ }^{58}$.

De esta forma, podemos analizar tales elementos del criterio KaldorHicks, como una secuencia temporal que se inicia con la labor del juez dictando una sentencia de atribución inmediata de ganadores y perdedores. En la figura siguiente se mostrará que ciertos elementos del concepto se verifican coetáneamente a la dictación de la sentencia, en cambio otros elementos, pueden verificarse con posterioridad a ella cuando se encuentra vigente la cosa juzgada que emana del fallo. Con todo, cada uno de esos elementos fueron valorados al momento de la dictación de la sentencia. El punto es que no todos esos elementos son de verificación coetánea al acto de decisión judicial. La figura No 1, posee la siguiente estructura:

\section{Figura No 1: Secuencia temporal de elementos del concepto} Kaldor-Hicks

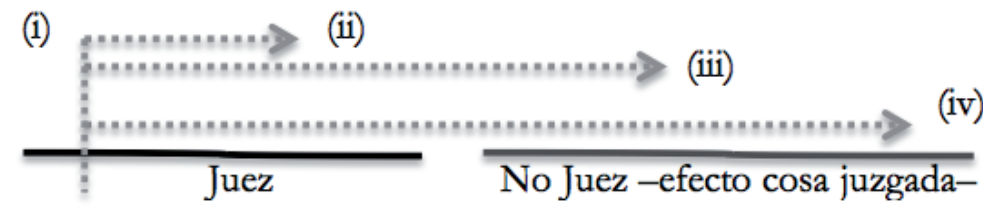

En este sentido, el juez al dictar la sentencia -elemento (i)-, genera una atribución inmediata de ganadores y perdedores -elemento (ii)-; de

que ese estado social es superior al estado social Y (persecución del bien), en atención a que el estado social Y genera menos riqueza para la masa (activos susceptibles de ser repartidos a los acreedores) que el estado social X, en razón de los costos de que trae consigo la persecución del bien. Sin embargo, nada impide que el liquidador pueda alcanzar un acuerdo con el tercero por medio del cual se produzca el reintegro de tal bien a la masa, en cuyo caso, el tercero primeramente ganador lo seguirá siendo si es que el precio que recibe por el bien es mayor a su valoración inicial para poseerlo (en este caso habría compensación).

58 Utilizando el factor de eficiencia Kaldor-Hicks, tenemos que, si bien la decisión judicial es la que genera los ganadores-perdedores, ella se basa en una elección previa entre diversas alternativas. Por lo mismo, podemos diferenciar la atribución inmediata de ganadoresperdedores -que se alcanza por medio de la decisión judicial-, y la atribución mediata de ganadores-perdedores -que viene dada por la elección de aquella opción disponible para el juez a efectos de adoptar la decisión judicial-. 
forma que los elementos siguientes, esto es, la existencia de una compensación -elemento (iii)-, y que la misma permita la subsistencia de una ganancia neta para los ganadores -elemento (iv)-, solo ocurrirá cuando haya cesado la labor del juez y las partes se rijan por el efecto de cosa juzgada.

Con todo, al momento de dictar sentencia -elemento (i)-, el juez no solamente efectúa una atribución inmediata de ganadores-perdedores, sino que también, valora la concurrencia de los elementos (iii) y (iv); sin embargo, la existencia en la práctica de estos últimos dos elementos es eventual, y para el caso hipotético que se verifiquen, ya no habrá juez conociendo del asunto.

Y ello es así, porque al momento de la decisión del juez -esto es, al momento (i) - para satisfacer las exigencias de eficiencia que se encuentran inmersas en la fundamentación de una decisión dictada en un subconjunto normativo donde es procedente el análisis económico del derecho, se requiere verificar la procedencia de todos los elementos que conforman el concepto del criterio Kaldor-Hicks [elementos (i), (ii), (iii) y (iv)].

Ahora bien, el hecho que solamente el elemento (ii) sea susceptible de ser constatado en la sentencia se debe a que por esencia el concepto Kaldor-Hicks supone una decisión con ganadores y perdedores, de forma que el juez no fallaría conforme a dicho criterio si es que no concurriera en su decisión el elemento (ii). La caracterización de la sentencia como un acto jurídico procesal dotado de coercitividad y respaldado con el efecto de cosa juzgada, impone la existencia de ganadores y perdedores dentro del acto decisional.

En cambio los elementos (iii) y (iv) solamente serán valorados en la sentencia, pero su verificación práctica ocurrirá potencialmente después que ella se dicte, ya que tal como hemos visto, la compensación en el criterio Kaldor-Hicks es ex post al acto decisional. En este sentido, la existencia de una compensación no es necesaria para la procedencia del criterio Kaldor-Hicks -elemento (iii). De la misma forma, también es posterior a la atribución inmediata de ganadores-perdedores, el elemento (iv) del concepto Kaldor-Hicks el que emerge solo una vez que exista compensación, a efectos de valorar si la compensación permite que los ganadores sigan siendo ganadores a pesar de dicha compensación.

La importancia de este análisis es que aliviamos la carga de información que debe tener el juez al momento de dictar sentencia en base a consideraciones de eficiencia conceptualizadas de acuerdo al criterio Kaldor-Hicks. En este sentido, el juez solo debe saber que está generado 
una atribución inmediata de ganadores-perdedores -elemento (ii)-, lo que trasunta en una débil carga de información porque esa atribución es la que realizan habitualmente los jueces. La valoración de la concurrencia de los otros dos elementos -(iii) y (iv) - es puramente prospectiva, o sea, hacia el futuro. El juez debe ponderar de acuerdo a la información disponible en el proceso civil que es probable que si ocurre una compensación -elemento (iii)-, los ganadores de su atribución inmediata seguirán siendo ganadores -elemento (iv)-.

En este sentido, siguiendo a Elster, podemos señalar que un procedimiento que busca la eficiencia es racional, si tiende a producir a largo plazo más creencias verdaderas (atribuciones de ganadores-perdedores correctas por medio de la utilización del criterio Kaldor-Hicks) que cualquier otro procedimiento, aun cuando en situaciones concretas la creencia así formada (la atribución de ganadores-perdedores) no se corresponda con la realidad ${ }^{59-60}$. De esta forma, si el procedimiento que resuelve asuntos con miras a la eficiencia no asegura que siempre y en todos los casos se conducirá a satisfacer completamente todos los elementos del criterio Kaldor-Hicks, ello no impide considerar racional ese procedimiento.

Ello es ratificado por Sen cuando indica que ciertos procedimientos de elección colectiva, como lo es, el procedimiento judicial aplicando un criterio de decisión de eficiencia, puede ser útil en ciertos casos para los fines que persigue -por ejemplo, obtención de mayor bienestar social-, y que su no aplicación para todos los casos posibles, no conduce a la invalidez del criterio ${ }^{61}$. En este sentido, este artículo no pretende sostener que la eficiencia es un factor relevante en todo el derecho, sino que en ciertos ámbitos donde claramente es un instrumento que plausiblemente conducirá a la consecución de los objetivos de obtención de mayor riqueza social.

En esos casos - usando la terminología de Sen-, o en esos subconjuntos normativos - usando la terminología de este trabajo-, en donde opera útilmente un criterio de decisión, como la eficiencia, se parte del supuesto que la operatividad del criterio se deriva de la forma en como están configuradas las preferencias reales de los sujetos implicados en tales casos o subconjuntos normativos.

\footnotetext{
59 Elster, John (1997) EGOnomics. Barcelona: Gedisa Editorial, p. 45.

60 En sentido similar, puede verse: Demsetz, Harold (1967) "Toward a Theory of Property Rights”. American Economic Review, Vol. 57, No 2, pp. 347-350.

61 En este sentido SEN (1976) 89, señala "La bondad de una CCR no es independiente de las configuraciones de preferencias reales, $y$ al pedir que funcione bien en todas las circunstancias uno podría eliminar reglas buenas que hubiesen servido bien en la mayoría de los casos, pero no en todos".
} 
Por tanto, el problema de la comparación interpersonal deja de ser un asunto relevante, ya que en la mayoría de tales casos o subconjuntos normativos, concurrirán supuestos de responsividad no negativa ${ }^{62}$, esto es, que para cualquier individuo de una sociedad la alternativa $\mathrm{X}$ (digamos, "mayor bienestar social"), no cede frente a la alternativa Y (digamos, "cualquier otra opción distinta a mayor bienestar social"), de forma que tampoco para la sociedad, la alternativa X cede frente a la alternativa $\mathrm{Y}$.

Tal como señalamos precedentemente, el derecho procesal concursal, es un caso o subconjunto normativo particular, donde opera la eficiencia, en el cual no es de extrañar que los partícipes de los procedimientos concursales estuvieran contestes en desear un objetivo de eficiencia de mayor tasa de recuperación de activos posibles. Dicha suposición de los partícipes de los procedimientos concursales ha sido reconocida por el legislador concursal en la forma en que ha regulado dicha normativa ${ }^{63}$, de forma

62 SEN (1976) 91.

63 Así por ejemplo emana de la Ley No 20.720 sobre Reorganización y Liquidación de Empresas y Personas. En el Proyecto de Ley con que se inició la tramitación que dio origen a dicha normativa, se señala en su exposición de motivos, la vinculación entre una legislación eficiente concursal y el desarrollo económico del país "Además, un procedimiento concursal más ágil y eficiente permite utilizar los recursos que quedan desaprovechados en esa empresa fallida en otras actividades, mejorando asi la productividad, permitiendo generar nuevos puestos de trabajo y aportando al crecimiento económico del pais". De esta forma, dicha normativa ha estructurado procedimientos de reorganización y liquidación de empresas y personas con miras a procedimientos concursales más rápidos, menos costosos y más eficientes. Algunos ejemplos, en ese sentido, son: (i) El artículo 58, que determina la procedencia de una propuesta de reorganización concursal ocurrirá solamente cuando la continuación de la actividad empresarial del deudor garantice su cumplimiento, y asimismo, cuando la mantención de dicha actividad, permita hacer frente a los compromisos que dieron origen a la dificultad crediticia del deudor. En otras palabras, el veedor informará favorablemente una reorganización empresarial cuando la marcha de la empresa sea viable, de forma que las dificultades que permitieron la entrada a la reorganización, se debió a problemas de liquidez. Con el examen, por parte del Veedor, de las consideraciones referidas, se trata de evitar un error tipo I concursal, esto es, aquel que impide que una empresa viable pueda continuar en funcionamiento a causa de problemas de liquidez. Si el examen del Veedor resulta contrario a la propuesta de reorganización, por no satisfacer las exigencias mencionadas, entonces, la mejor alternativa para la empresa en dificultades, es la liquidación; (ii) Normas que tienden a disminuir los trámites de realización, como lo es la regulación de la oferta de compras directas (artículos 222 y 223 de la Ley No 20.720), o bien, la delimitación de los supuestos de realización sumaria de activos (artículo 204 de la Ley No 20.720), y (iii) La reducción de costos se pretende obtener por medio de la posibilidad de establecer votaciones electrónicas en el marco de ciertas decisiones de Juntas de Accionistas, como ocurre con la opción de proceder a la votación por medio de firma electrónica avanzada respecto de decisiones a ser adoptadas en el procedimiento de reorganización concursal (artículo 80 de la Ley No 20.720). Esto posibilita un mejor funcionamiento de las Juntas de Acreedores, que poseen la virtud de establecer un contexto para la coordinación de intereses de acreedores, y con ello reducir los costos de una litigación diseminada. Sin embargo, si la regulación establece exigencias, y cargas demasiado onerosas para el funcionamiento y adopción de acuerdo de las Juntas de Acreedores, entonces, el costo de su funcionamiento superará los beneficios 
que la idea que la concurrencia de supuestos de responsividad no negativa, puede que no sea muy extrańa en esos casos o subconjuntos normativos.

Cabe señalar que la responsividad no negativa satisface exigencias de aciclicidad, esto es, si la alternativa $\mathrm{X}_{1}$ es preferida a $\mathrm{X}_{2}, \mathrm{X}_{2}$ a $\mathrm{X}_{3}$, y así sucesivamente hasta, entonces, la aciclicidad exige que $\mathrm{X}_{1}$ sea considerada al menos tan buena como $\mathrm{X}_{1}$.

La aciclicidad es una condición más tenue que la transitividad. Esta última supone una preferencia estricta entre ternas, de forma que si $\mathrm{X}_{1}$ es preferida a $\mathrm{X}_{2}, \mathrm{y} \mathrm{X}_{2}$ es preferida a $\mathrm{X}_{3}$, entonces, $\mathrm{X}_{1}$ es preferida a $\mathrm{X}_{3}$. En términos tales que si se cumple dicha transitividad en la totalidad de las ternas, entonces, la transitividad se cumple para todo el conjunto ${ }^{64}$. En este sentido si, $\mathrm{x}_{1} \mathrm{P} \mathrm{x}_{2}$, representa una relación binaria según la cual " $\mathrm{x}_{1}$ prefiere en un subconjunto $\mathrm{P}$ a $\mathrm{x}_{2}$ ", en el contexto de un conjunto, $\mathrm{S}$, tenemos que: para todo $\mathrm{X}_{1}, \mathrm{X}_{2} \mathrm{y} \mathrm{X}_{3}$ perteneciente al conjunto $\mathrm{S}$ : $\left(\mathrm{x}_{1} \mathrm{P} \mathrm{x}_{2} \&\right.$ $\left.\mathrm{x}_{2} \mathrm{P} \mathrm{x}_{3}\right) \mathrm{x}_{1} \mathrm{P} \mathrm{x}_{3}$.

Sin embargo, una relación de preferencia puede ser acíclica sobre todas las ternas, pero infringir la aciclicidad en el conjunto. Por ejemplo, supongamos que tenemos 2 personas en una sociedad ( $\mathrm{A}$ y B), y las preferencias de $\mathrm{A}$ sobre los estados sociales alternativos es: $\mathrm{X}>\mathrm{Y} \mathrm{Y}>\mathrm{Z}$, en circunstancias que las preferencias de $\mathrm{B}$ sobre esos mismos estados sociales alternativos es: $Y>Z$ Z $>X$. En este caso, en el par (Y, Z), Y es socialmente preferida a $Z$ (ello ocurre tanto según las preferencias de $\mathrm{A} y \mathrm{~B}$ ), pero en los pares $(\mathrm{X}, \mathrm{Y})$ y $(\mathrm{X}, \mathrm{Z})$, existe situación de indiferencia ${ }^{65}$ (ello debido a que no existe una preferencia estricta de $\mathrm{A}$ y $\mathrm{B}$ respecto de dichos pares). Con todo, en este ejemplo, tenemos una mejor alternativa en cada subconjunto $(Y>Z$, tanto para A como para $B)$, pero no sobre el total (preferencias de $\mathrm{A}$ y $\mathrm{B}$ sobre las alternativas $\mathrm{X}, \mathrm{Y}, \mathrm{Z})$.

Según Sen, la aciclicidad da lugar a reglas de elección colectivas que permite determinar una mejor decisión en subconjuntos determinados. Uno de tales subconjuntos puede ser aquellos subconjuntos normativos que nosotros hemos identificado donde opera la eficiencia. En este sentido, una decisión judicial adoptada en tales subconjuntos normativos que tienda hacia la eficiencia, puede entregar una mejor decisión en ese contexto, pero ello no significa que esa regla de elección colectiva aplique en todo el conjunto, por ejemplo, a la totalidad del sistema jurídico. Esto es relevante porque permite fundamentar mejores decisiones en base a deter-

que se espera obtener de ella. Por lo mismo, el establecimiento de sistemas de votación electrónica a distancia, favorece la obtención de quórums, y la participación de acreedores. 
minadas reglas de elección social -eficiencia, justicia, equidad, etc.-, en ciertos subconjuntos normativos, sin que se imponga la necesidad lógicajurídica de buscar un único factor que permita resolver los conflictos o asuntos que surjan en el sistema jurídico como un todo.

Adicionalmente, la aciclicidad resulta admisible en el contexto de decisión del proceso civil, porque es la cualidad lógica que más cercanía tiene con el estándar de convicción de preponderancia de prueba. Dicho estándar significa que en el proceso civil vence aquella parte que logra probar mejor que la otra los hechos, sin que se exija como en el proceso penal, convicción más allá de toda duda razonable ${ }^{66}$. Lo que nos basta saber ahora, es que dicho estándar no nos conduce a lo que se denomina habitualmente como "verdad material", esto es, la necesidad de traspasar al proceso los hechos relevantes del asunto, acaecidos fuera del juicio, tal como ocurrieron ${ }^{67}$.

En este sentido, la aciclicidad se transforma en una cualidad lógica adecuada al estándar de prueba del proceso civil, toda vez que le fija al juez una regla de elección social por medio de la cual el juzgador debe escoger aquella alternativa que, en el subconjunto normativo respectivo, sea al menos tan buena como otra alternativa rival ${ }^{68}$.

66 Al respecto puede verse: (i) LARroucau, Jorge (2012) "Hacia un estándar de prueba civil". Revista Chilena de Derecho, Vol. 39, N³, pp. 783-808; (ii) Tavolari, Raúl (1999) "Valoración sobre la prueba en el proceso (Viejos y nuevos temas probatorios)". Revista de Derecho y Jurisprudencia, t. XCV, pp. 37-59.

67 En este sentido: (i) TARUfFo, Michele (2003) "Algunas consideraciones sobre la relación entre prueba y verdad”. Discusiones: Prueba y conocimiento, No 3. Disponible en: http://www. cervantesvirtual.com/nd/ark:/59851/bmckk9s2 [última visita 26 de diciembre de 2015], p. 37; (ii) Así, Taruffo en su artículo Verdad, prueba y motivación en la decisión sobre los hechos, señala que "Por un lado, como se ha dicho anteriormente, no está en duda que la verdad de la cual se puede hablar en el ámbito del proceso es relativa, contextual, aproximada y dependiente de la cantidad y la calidad de la informaciones que las pruebas introducen en el proceso". TARuffo, Michelle (2013) "Verdad, prueba y motivación en la decisión sobre los hechos". Cuadernos de Divulgación de la Justicia Electoral, No 20. México: Tribunal Electoral del Poder Judicial de la Federación, p. 40.

68 Esta idea puede traer consigo que alguien piense que la aciclicidad no es procedente en el derecho procesal, porque en esta área jurídica se enfrentan dos alterativas (la del demandante y la del demandado), y la aciclicidad significa una decisión en ternas. Sin embargo, en el sistema procesal civil rige el principio de iura novit curia, según el cual, "el derecho lo conoce el juez". Dicho principio en términos sencillos significa que el juez no queda limitado por las alternativas de interpretación jurídica de las partes, de forma tal que puede introducir una calificación jurídica diversa, o sea una tercera alternativa. De esta forma, en la generalidad de los casos, en el derecho procesal también existen al menos tres alternativas de decisión: la que sostiene el demandante, la que sostiene el demandado y la que sostiene el juzgador. Al respecto revisar: (i) Hunter, Iván (2013) "Iura novit curia y el proyecto de Código Procesal Civil: ¿Para qué sirve definir los poderes del juez en la aplicación del Derecho?". Revista de Derecho de la Pontificia Universidad Católica de Valparaíso, No 40, pp. 601-640, y (ii) Hunter, Iván (2010) "Iura Novit Curia en la jurisprudencia civil chilena". Revista de Derecho de Valdivia, Vol. 23, No 2, pp. 197-221. 
Así, no se requiere que el juez conozca a tal nivel la calidad veritativa de los enunciados fácticos que conforman las alternativas en pugna, en términos de preferencia estricta, como sería que el juez considere que la alternativa de decisión $\mathrm{X}_{1}>\mathrm{X}_{2}$, o en términos de la relación binaria anterior que: $\mathrm{x}_{1} \mathrm{P} \mathrm{x}_{2}$.

Basta que el juez considere que una de las alternativas en pugna sea al menos tan buena como otra, para decidirse por alguna de ellas. De forma que al juez le basta frente a $n$ alternativas, decidirse por: $\mathrm{X}_{1}$, en la medida que considere a $\mathrm{X}_{1}$, tan buena como alguna de las otras alternativas rivales.

Dicha decisión acíclica en base a preponderancia de prueba se encuentra plenamente justificada en el proceso civil, ya que no le exigimos al juez que adquiera un conocimiento exacto de la veracidad de cada una de las alternativas. Ello queda en evidencia con el ejemplo del demandante ganancioso que no rinde prueba alguna ${ }^{69}$.

Evidentemente el juez fundamentará las razones por las que considera a la alternativa, $\mathrm{X}_{1}$, como la alternativa ganadora en una disputa entre $n$ alternativas rivales. En este sentido, si la prueba no conduce a dar primacía a una alternativa sobre otra, factores tales como la carga de la prue-

69 En este sentido, considerar el siguiente ejemplo: (i) En un sistema civil de preponderancia de prueba, obtiene un resultado favorable quien acredita relativamente mejor sus formulaciones argumentativas que fundamentan la pretensión respectiva. En consecuencia, la no prueba de un hecho alegado por el demandante y del cual dependa la existencia de una determinada pretensión no significa la falsedad del hecho en cuestión, sino que solamente trae como consecuencia que no se habrá probado la confirmación de la verdad de la hipótesis en que se fundó la pretensión, de manera que la acción será desestimada; (ii) Ello nos permite avanzar, en la idea que lo que se encuentra afecto a acreditación en el marco del proceso civil, es la verdad de las hipótesis en que se sustentan las pretensiones y defensas de las partes, en los términos y contextos formulados, las que serán acreditadas de acuerdo a las cargas que determinen las reglas del onus probandi; (iii) Con todo, el cumplimiento o no de los requerimientos de conducta que se exijan para acreditar dichas hipótesis determinará la necesidad de dar probada o no la verdad de las mismas. Por ejemplo, si respecto de la prueba de un determinado suceso fáctico el demandante acompańa un documento del cual se infiere directamente la existencia del hecho en cuestión, el mismo resultará probado, pudiendo afirmarse la verdad de la hipótesis de la pretensión del actor. Por el contrario, si el demandado ha alegado hechos extintivos al fundamento del demandante -reconoce la existencia de los hechos que fundan la demanda, pero alega su extinción-, y no los acredita -insatisfacción de su hipótesis de defensa-, se tendrá por probado el hecho que funda la acción -aun cuando el actor no acompañe el antecedente que funda su hipótesis activa-, todo ello, por incumplimiento de la carga de prueba del demandado; (iv) De esta manera, el actor no siempre requerirá una prueba equivalente o superior al 50\% de la verdad de la hipótesis de la pretensión respectiva, ya que, en ciertos casos, dependiendo de las alegaciones del demandado, no será necesario exigirle ninguna prueba de preponderancia en la medida que el demandado tampoco haya aportado ningún medio que demuestre la plausibilidad de la verdad de la hipótesis de defensa que sea impeditiva o extintiva de la hipótesis activa. Lo contrario, podría suponer exigencias de pruebas imposibles para el actor (carga de probar el hecho negativo que desacredita la existencia de la hipótesis de defensa alegada por el demandado). 
ba, los principios aplicables en ese subconjunto normativo, o alguna otra metaeregla determinarán la fundamentación de la elección a favor de $\mathrm{X}_{1}$.

Finalmente, la aciclicidad en el contexto especial del derecho procesal civil, permite no ser tan pesimista respecto del asunto de las comparaciones interpersonales. En efecto, las partes tienen la opción por mecanismos de internalización de rendir la prueba y realizar las inversiones en juicio que permitan satisfacer sus pretensiones o defensas ${ }^{70}$. Pues bien, al permitir la regla de aciclicidad que triunfe aquella posición que alcance una solución adecuada en un subconjunto específico, ello se traduce en imponer a las partes la necesidad de internalizar el costo de dar a conocer las razones que hacen que su alternativa deba ser preferida a la alternativa rival.

En este sentido, si el primer elemento determinaba que la eficiencia -entendida como mejoras en bienestar o utilidad- es deseable en ciertos subconjuntos normativos, entonces, será de cargo de cada parte soportar el costo de entregar en juicio la información que permita dar a conocer sus posiciones relativas en términos de bienestar o utilidad.

De esta forma, si una parte prevalece en ese esfuerzo, entonces, su triunfo se reflejará en la decisión de adjudicación del juez, que supone una comparación interpersonal con la alternativa que sostiene la parte perdedora, en términos acíclicos en base a un estándar de preponderancia. Si ambas partes igualan en ese esfuerzo -esto es, prueban que una decisión favorable a ellos es la que genera mayor bienestar social-, el juez tendrá que recurrir a metarreglas, normas de carga de prueba u otros principios, para fundar su fallo acíclico en base a un estándar de preponderancia.

70 En el proceso civil, las partes internalizan los costos de litigación ponderando que tendrán una sola oportunidad para acreditar sus posiciones, por lo que el costo de cumplimiento de la carga de prueba se podrá distribuir a lo largo del juicio, pero en todo caso se agotará en el proceso como juego único, de forma que a las partes no les sirve que se guarde nada para después del proceso, porque su alternativa de probanza se habrá frustrado, por haber operado la regla de incumplimiento de carga probatoria. El juego único, induce a sincerar las pruebas que admiten un resultado favorable para el sistema jurídico. Si la parte no posee la forma de allegar esas pruebas en este juego único, entonces, hay justicia en el resultado que determina el rechazo de su demanda. Detrás de esa razón de juego único procesal como vía de internalización se encuentra el rechazo a la intuición de tener que favorecer que las partes prueben sus elementos de pretensión o defensas, en circunstancias que el proceso civil no tiene por qué favorecer ninguna necesidad de prueba, según puede verse: Picó I Junoy, Joan (1997) Las garantías constitucionales del proceso. Barcelona: Bosch Editor, p. 132. Por el contrario, el juez debe tratar como iguales a las partes, entendida esa igualdad como una posición neutral del juez frente a aquello que potencialmente allegarán las partes al juicio en cumplimiento de sus cargas probatorias, según puede verse: Hunter, Iván (2011) "La iniciativa probatoria del juez y la igualdad de armas en el proyecto de código procesal civil”. Revista Ius et Praxis, Año 17, No 2, p. 54. 
En ambos casos concurren dos circunstancias. Primero, en ambos supuestos existe necesidad de comparación interpersonal, precisamente porque el factor de decisión en el subconjunto normativo donde aplica la eficiencia, favorece la alternativa que genere mayor bienestar social, de forma tal que se debe elegir aquella alternativa que conduce a ese objetivo, lo que supone comparar interpersonalmente los niveles de bienestar o utilidad que tales opciones traen consigo. Segundo, en ambos casos la realización de una comparación interpersonal está efectuada en función de los esfuerzos de las mismas partes interesadas. Lo que en un contexto dispositivo -como el que rige en el proceso civil-, significa trasladar parte de la responsabilidad de la corrección de la comparación interpersonal a los mismos interesados y no aquel que decide. En esto último, el derecho procesal civil se constituye como un ámbito particular de decisión de conflictos sociales, donde se disminuye la problemática de tales comparaciones.

\section{CONCLUSIONES}

De lo expuesto en este trabajo se pueden desprender las siguientes conclusiones:

1. El criterio Kaldor-Hicks al introducir los conceptos de perdedores y ganadores, reingresa a la teoría de la decisión social, el problema de la comparación interpersonal de utilidades que Pareto pretendió dejar de lado (regla imparcial de decisión).

2. En este sentido, existe la pretensión de que las comparaciones interpersonales no son necesarias cuando nos enfrentamos a un criterio objetivo, esto es, a un criterio que no dependa de juicios de valor. En este sentido, los criterios Paretianos al pretender establecer reglas que fueran unánimemente aceptadas por todos, buscaban un factor imparcial de resolución de elecciones colectivas. Así, por ejemplo, el óptimo de Pareto al establecer el tránsito desde la sociedad $\mathrm{X}$ a la sociedad $\mathrm{Y}$, sin que existieran perdedores, buscaba precisamente que no existiera oposición al movimiento que nos condujera a la sociedad $\mathrm{Y}$.

3. Existe, por tanto, una imposibilidad empírica derivada del hecho que existan juicios de valor involucrados en relación al criterio sobre qué factor debería primar en una determinada decisión, que por ejemplo, esté gobernada por un factor de eficiencia que tiende a generar mayor bienestar social. De esta forma, si la discusión recae en juicios de valor, entonces, no sería posible por medio de un análisis científico comparar las magnitudes de (in)satisfacción de los sujetos implicados. 
4. Las comparaciones interpersonales para la economía suponen la posibilidad de ponderar los niveles de ganancias o bienestar y las pérdidas marginales de bienestar de los individuos. En este sentido, la idea de comparación interpersonal supone siempre la idea de una "mejor opción”, en términos tales que esa mejor opción es elegida en el contexto de las comparaciones entre los sujetos implicados.

5. En el contexto de una decisión social, donde el factor a utilizar promueva la eficiencia, se debe escoger aquella alternativa que conduzca a mayor bienestar social futuro, aun cuando genere perdedores.

6. El problema de la comparación interpersonal resulta complejo, toda vez que, normalmente compararemos utilidad. Con dicho concepto se quiere reflejar toda las valoraciones que poseen las personas tengan o no una apreciación pecuniaria, lo que incluye bienes y servicios que no se transan en un mercado.

7. Lo relevante es que una variación de riqueza no es completamente correlativa a una variación de utilidad, precisamente porque no se trata de conceptos sinónimos y adicionalmente, debido a que cada persona valorará de manera distinta un cambio en las situaciones de riqueza, en razón de la ley de la utilidad marginal decreciente, que se traduce en que a medida que una persona adquiere unidades adicionales de un bien o servicio, la utilidad aumenta pero en una tasa decreciente. Así, el concepto de riqueza (medido por lo que las personas adquieren) y utilidad (el provecho que las personas obtienen de bienes o servicios, incluso aquellos que no poseen apreciación pecuniaria), se van diferenciando al producirse tales incrementos marginales o adicionales.

8. Al respecto, han fracasado los intentos de resolver la medición de tal comparación interpersonal de utilidad que han sido ensayados por los economistas (Gooman/Markowitz, 1952; Von Neumann-Morgenstern, 1944). Sen ha propuesto un mecanismo de comparación interpersonal de utilidades parcial (1976), según la cual es posible alcanzar una elección óptima sin caer en los extremos de no comparabilidad ni comparabilidad completa. Sin embargo, tal solución no es aplicable al derecho procesal civil porque en el acto de adjudicación no se puede realizar un ejercicio de comparabilidad parcial como el propuesto por Sen, porque nos enfrentamos a 2 individuos y el análisis mencionado, supone que desechamos la correspondencia de uno a uno, por una comparación de muchos a muchos.

9. Como consecuencia de ello constatamos que en el acto jurídico procesal de decisión jurisdiccional necesariamente nos enfrentaremos a las problemáticas de la comparación interpersonal. Lo anterior, por la sencilla razón de que el acto de adjudicación genera ganadores y perdedores. Así, sostener críticamente una posición a los criterios de 
eficiencia por generar tal comparación, no aplica al derecho procesal, porque dicha área está estructurada para producir precisamente las dificultades que trae consigo la comparación interpersonal de utilidades.

10. Con todo, otros factores de decisión provenientes desde la teoría moral están afectos a las mismas dificultades de comparación interpersonal, incluso aquellas fundadas en fundamentos de justicia, equidad e igualdad (Suppes 1966; Dworkin, 2008; Rawls, 2006).

11. Con todo, en el derecho procesal civil, confluyen dos elementos que pueden dar una solución al problema de la comparación interpersonal: (i) el primero de ellos, es considerar al criterio Kaldor-Hicks como factor de decisión social que da contenido a la eficiencia, $y$ que opera como un instrumento que conduce en ciertos subconjuntos normativos a alcanzar un fin de mayor bienestar social con más certeza que otro instrumento, y (ii) en segundo lugar, la decisión del juez opera en el proceso civil con márgenes de error que permiten que la elección judicial opere en búsqueda no de la mejor elección, sino a lo menos, de una que opere "como si" fuese la mejor.

12. El elemento (i) anterior, genera que la comparación interpersonal no sea relevante en ciertos subconjuntos normativos, y el elemento (ii) precedente, determina que el proceso civil está configurado para una elección acíclica (“como sî̀), lo que disminuye las problemáticas de una comparación interpersonal.

\section{BibLIOGRAFÍA}

Aghion, Philippe; Hart, Oliver; Moore, John (1992) “The Economics of Bankruptcy Reform". Journal of Law, Economics and Organization, Vol. 8, No 3, pp. 523-546.

Agüero, Francisco; García de Cortázar, Verónica; García, William (2013) "Control Jurisdiccional de la potestad normativa del Tribunal de Defensa de la Libre Competencia en materia de telecomunicaciones". Informe en Derecho, No 26. Santiago: REGCOM, Facultad de Derecho de la Universidad de Chile, 59 pp.

Cabrillo, Francisco (1998) Quiebra y liquidación de empresas. Madrid: Unión Editorial, 151 pp.

Carrasco, Nicolás (2010) "La contracautela: Una mirada desde el análisis económico del derecho procesal". Revista de Derecho y Humanidades, Vol. 2, No 16, pp. 171-185.

Carrasco, Nicolás y Núñez, Raúl (2015) "Análisis Económico de la Administración de Justicia ¿La justicia como bien público o privado?". Revista Chilena del Derecho, Vol. 42, No 2, pp. 595-613. 
Carrasco, Nicolás y NúŃEz, Raúl (2014) “Conceptos generales del Análisis Económico del Derecho Concursal”. En Carrasco, Nicolás y Núnez, Raúl (coordinadores): Presente y Futuro del Derecho Procesal Concursal Chileno. Una revisión desde el Análisis Económico del Derecho. Santiago: Editorial LegalPublishing, pp. 25-53.

Coleman, Jules (1980) "Efficiency, Exchange, and Auction: Philosophic Aspects of the Economic Approach to Law". California Law Review, Vol. 68, N² 2, pp. 221-249.

Coleman, Jules (2004) "Los Fundamentos del Bienestar". Revista de Derechos y Humanidades, $\mathrm{N}^{\circ} 10$, pp. 17-46.

Cornelli, Francesca, y Felli, Leonardo (1997) "Ex ante efficiency of bankruptcy procedures". European Economic Review, Vol. 41, pp. 475-485.

Couture, Eduardo (2010) Estudios de derecho procesal civil. Vol. I. Buenos Aires: Editorial La Ley.

Dworkin, Ronald (1998) “¿Es la riqueza un valor?”. Revista Estudios Públicos, $\mathrm{N}^{\circ}$ 69, pp. 259-298.

Demsetz, Harold (1967) "Toward a Theory of Property Rights". American Economic Review, Vol. 57, No 2, pp. 347-359.

Dworkin, Ronald (2008) El imperio de la justicia. Barcelona: Gedisa Editorial, 328 pp.

Elster, John (1997) EGOnomics. Barcelona: Gedisa Editorial, 214 pp.

Goodman, Leo y Markowitz, Harry (1952) "Social Welfare Functions Based on Individual Rankings". American Journal of Sociology, Vol. 58, No 3, pp. 257-262.

Hicks, John (1939) "The Foundations of Welfare Economics". The Economic Journal, Vol. 49, No 196, pp. 696-712.

Hare, Richard (2003) The Language of Morales. Oxford: Oxford University Press, pp. 129-134, 208 pp.

Harsanyi, John. (1955) "Cardinal Welfare, Individualistic Ethics and Interpersonal Comparison of Utility". The Journal of Political Economy, Vol. 63, No 4, pp. 309-321.

Hart, Oliver (2000) "Different approaches to Bankruptcy". National Bureu of Economic Research. Disponible en: [fecha de visita 4 de diciembre de 2015], 18 pp.

Hicks, John (1941) "The Rehabilitation of Consumers' Surplus". Review of Economic Studies, Vol. 8, pp. 108-116.

Hovenkamp, Herbert (1990) "Positivism in Law \& Economics". California Law Review, Vol. 78, No 4, pp. 2229-2269.

Hunter, Iván (2011) "La iniciativa probatoria del juez y la igualdad de armas en el proyecto de código procesal civil". Revista Ius et Praxis. Ańo 17, No 2, pp. 53-76.

Hunter, Iván (2010) "Iura Novit Curia en la jurisprudencia civil chilena". Revista de Derecho de Valdivia, Vol. 23, No 2, pp. 197-221. 
Hunter, Iván (2013) "Iura novit curia y el proyecto de Código Procesal Civil: ¿Para qué sirve definir los poderes del juez en la aplicación del Derecho?". Revista de Derecho de la Pontificia Universidad Católica de Valparaiso, No 40, pp. 601-640.

Jhunjhunwala, Bharat (1974) "Kaldor-Hicks-Scitovszky Criteria: A postmortem”. Southern Economic Journal, Vol. 40, N³, pp. 493496.

Kaldor, Nicholas (1939) "Welfare Propositions of Economics and Interpersonal Comparisons of Utility". The Economic Journal, Vol. $49, \mathrm{~N}^{\circ} 195$, pp. 549-552.

Larroucau, Jorge (2012) "Hacia un estándar de prueba civil". Revista Chilena de Derecho, Vol. 39, $\mathrm{N}^{\circ}$ 3, pp. 783-808.

Manassero, Ana y Muñoz, Hugo (2014) "El proceso como sistema en el estado de derecho”. Revista Jurídica, Vol. 2, No 1, pp. 105-128.

Marschak, Jacob (1950) "Rational Behavior, Uncertain Prospects, and Measurable Utility”. Econometrica, Vol. 18, No 2, pp. 111-141.

MontT, Santiago (2010) "El TDLC como ente regulador del comercio". Documento de Trabajo No 1. Santiago: REGCOM, Facultad de Derecho de la Universidad de Chile, 18 pp.

Muñoz, Félix (2002) "Teoría del Consumo". En Cabañes, María Lucía (coordinadora): Microeconomía esencial. Barcelona: Ariel, pp. 66-83.

Peinado, Juan Ignacio (2006) "Cooperación y pillaje en el concurso". En Peinado, Juan Ignacio y Valenzuela, Francisco Javier (coordinadores): Estudios de Derecho Concursal. Madrid: Marcial Pons, pp. 231-257.

Picó I Junoy, Joan (1997) Las garantias constitucionales del proceso. Barcelona: Bosch Editor, 204 pp.

Posner, Richard (1998) "Utilitarismo, Economía y Teoría del Derecho". Revista Estudios Públicos, No 69, pp. 207-257.

Rawls, John (1999) Collected Papers. Editor Samuel Freeman. Harvard University Press, $672 \mathrm{pp}$.

Rawls, John (2006) Teoría de la Justicia. Traducción de María D. González. Buenos Aires: Fondo de Cultura Económica.

RiвotтA, Silvana (2011) "Necesidades, igualdad y justicia. Construyendo una propuesta igualitaria de necesidades básicas”. Derecho y Libertades, No 24 II, pp. 259-299.

Robbins, Lionel (1932) An Essay on the Nature and Significance of Economic Science. Londres: Macmillan \& CO., Limited, 156 pp.

SEN, Amartya (1976) Elección colectiva y bienestar social. Madrid: Alianza Editorial, 266 pp.

Shäfer, Hans-Bernd y Oтt, Claus (2004) The Economic Analysis of Civil Law. Londres: Edward Elgar, 488 pp.

Suppes, Patrick (1966) "Some Formal Models of Grading Principles". Synthese, Vol. 16, No 3, pp. 284-306. 
Tapia, Javier y Cordero, Luis (2015) "La revisión judicial de las decisiones regulatorias: Una mirada institucional". Revista Estudios Públicos, No 139, pp. 7-65.

TARuffo, Michele (2003) "Algunas consideraciones sobre la relación entre prueba y verdad". Discusiones: Prueba y conocimiento, No 3. Disponible en: http://www.cervantesvirtual.com/nd/ark:/59851/ bmckk9s2 [última visita 26 de diciembre de 2015], pp. 15-41.

TARuffo, Michele (2013) "Verdad, prueba y motivación en la decisión sobre los hechos". Cuadernos de Divulgación de la Justicia Electoral, No 20. México: Tribunal Electoral del Poder Judicial de la Federación, 110 pp.

TAVOlari, Raúl (1999) "Valoración sobre la prueba en el proceso (Viejos y nuevos temas probatorios)". Revista de Derecho y Jurisprudencia, t. XCV, pp. 37-59.

Von Neumann, John y Morgenstern, Oskar (1944) Theory of Games and Economic Behavior, Princeton: Princeton University Press, 625 pp.

Zhou, Qi (2005) The evolution of Efficiency Principle: From Utilitarianism to Wealth Maximization. Disponible en: http://ssrn.com/ abstract $=870748$, [fecha de visita 6 de noviembre de 2015], 20 pp.

Zimmerling, Ruth (1990) "Necesidades básicas y relativismo moral". Doxa, No 7, pp. 35-54. 